\title{
AVALIAÇÃO DO MICROCLIMA DE INSTALAÇÕES PARA GADO DE LEITE COM DIFERENTES RECURSOS DE CLIMATIZAÇÃO ${ }^{1}$
}

\section{LUCIANE S. MARTELLO ${ }^{2}$, HOLMER SAVASTANO JÚNIOR ${ }^{3}$, MARIA DAS G. PINHEIRO $^{4}$, SAULO DA L. E SILVA ${ }^{5}$, LUIZ C. ROMA JÚNIOR ${ }^{6}$}

\begin{abstract}
RESUMO: Este trabalho foi realizado no verão de 2002 e teve como objetivo avaliar a influência de alguns recursos de climatização no microclima interno das instalações. Foram utilizadas três instalações: i) controle; ii) com aspersão associada à ventilação, e iii) com tela de sombreamento. Os dados climáticos de cada instalação foram registrados e, posteriormente, calculados os índices de temperatura e umidade, do globo negro e umidade e a entalpia. Foram selecionados e analisados 26 dias com entalpia elevada. Os índices de temperatura e umidade (ITU) e de temperatura do globo e umidade (ITGU), nos horários mais quentes do dia, diferenciaram-se para a instalação climatizada (ii), que apresentou melhor desempenho em relação às demais. A entalpia menor foi observada no tratamento com tela (iii).
\end{abstract}

PALAVRAS-CHAVE: estresse calórico, gado de leite, índice de conforto térmico.

\section{EVALUATION OF DAIRY HOUSING ENVIRONMENT WITH DIFFERENT CLIMATIC SYSTEMS}

SUMMARY: This work was carried out during the summer of 2002 and the objective was to evaluate the influence of some cooling systems inside a housing. Three housing systems were used: i) control housing; ii) housing with mist and fans, and iii) shade cloth. The climatic data of each housing were registered to calculate the temperature humidity index (THI), the black globe humidity index (BGHI) and the enthalpy. Twenty six days with high enthalpy were selected and analyzed. Temperature humidity index (THI) and black globe humidity index (BGHI), in the hottest registration times, were able to differentiate the climatic housing, which shows better performance than the others. The lower enthalpy was observed in the shade cloth treatment.

KEYWORDS: heat stress, dairy cow, thermal comfort index.

\footnotetext{
${ }^{1}$ Parte da dissertação de mestrado do primeiro autor, apresentada à Faculdade de Zootecnia e Engenharia de Alimentos (FZEA/USP). Projeto financiado pela FAPESP e pela CAPES.

${ }^{2}$ Zootecnista, aluna de doutorado da FZEA/USP, Pirassununga - SP, Cx. Postal.: 23, Fone: (0XX19) 35654176, e-mail: martello@usp.br

${ }^{3}$ Eng $^{\circ}$ Civil, Prof. Associado, Departamento de Zootecnia, FZEA/USP, Pirassununga - SP, Bolsista CNPq PQ 2C.

${ }^{4}$ Zootecnista, Pesquisadora do Pólo Regional de Desenvolvimento Tecnológico dos Agronegócios do Centro Leste, IZ/Ribeirão Preto SP.

${ }^{5}$ Zootecnista, aluno de doutorado da FZEA/USP.

${ }^{6}$ Eng. Agrônomo, aluno de mestrado da FZEA/USP.

Recebido pelo Conselho Editorial em: 13-6-2003
}

Aprovado pelo Conselho Editorial em: 5-5-2004 


\section{INTRODUÇÃO}

Os elementos climáticos, tais como temperatura, umidade relativa e vento, entre outros, interferem significativamente na produtividade. Essa influência é mais intensa na utilização de animais geneticamente melhorados. A produção ótima dependerá, em grande parte, de construções e de manejo adequados que contornem os efeitos provocados pelo ambiente.

Existem vários indicativos para caracterizar o ambiente em termos de conforto e bem-estar animal, entre os quais estão os índices de conforto térmico, determinados com base nas variações dos valores das variáveis climáticas. A utilização de um índice de avaliação do conforto para determinada espécie animal, portanto, deve considerar, além das características inerentes ao animal, o tipo de ambiente (aberto ou fechado) e a importância relativa de cada elemento meteorológico envolvido. A dificuldade do uso generalizado dos índices ocorre pelo motivo de que alguns deles têm o objetivo de determinar a adequação de um ambiente com relação a uma atividade ou a um tipo específico de animal.

O índice de temperatura e umidade (ITU) foi desenvolvido originalmente por THOM (1959) como um índice de conforto térmico humano. Posteriormente, JOHNSON et al. (1962) e CARGILL \& STEWART (1966) observaram quedas significativas na produção de leite de vacas, associadas ao aumento no valor de ITU. De acordo com BUFFINGTON et al. (1981), é o índice mais utilizado pela maioria dos pesquisadores para avaliação do conforto em animais, em razão da facilidade de obtenção dos dados de temperatura e umidade relativa do ar, variáveis inseridas na fórmula do ITU. JOHNSON (1980) considerou que ITU a partir de 72 apresentava situação de estresse para vacas holandesas.

O índice de temperatura do globo e umidade (ITGU) foi desenvolvido por BUFFINGTON et al. (1981) como um índice ambiental para a caracterização do conforto térmico de vacas leiteiras expostas a ambientes com radiação solar direta e indireta. No cálculo do ITGU, considera-se a temperatura do globo negro substituindo a temperatura do bulbo seco na equação do ITU. De acordo com KELLY \& BOND (1971), sob condições de clima tropical, o animal pode estar exposto a carga térmica radiante, com alto nível de desconforto. Nesse caso, o ITU não reflete o ambiente térmico e não seria o mais adequado para avaliar o desconforto e as subseqüentes perdas na produção sob essas condições.

As limitações para obtenção de altos índices zootécnicos, no Brasil, decorrem do fato de animais geneticamente desenvolvidos em clima mais ameno serem alojados em ambientes de clima quente, porém em instalações projetadas com base em conceitos construtivos provenientes daquele clima (NÄ̈̈S \& SILVA, 1998).

A melhor sombra é proporcionada pelas árvores, isoladas ou em grupos (SILVA, 1988 citado por BACCARI, 1998). Porém, na ausência dessas, lança-se mão de sombras artificiais, do tipo móvel ou permanente. A móvel, como a tela de fibra sintética (polietileno), em conjunto com estruturas simples de metal ou madeira, pode prover de 30 a $90 \%$ de sombra de acordo com a abertura da rede.

Basicamente, a climatização de ambientes, por meios artificiais, dá-se por aspersão de água na cobertura, ventilação forçada, nebulização ou aspersão de água nos animais, associados ou não uns aos outros. BACCARI (2001) e BRAY et al. (1994) classificaram os sistemas de resfriamento evaporativo (SRE) em mist ou fog. No sistema mist, as gotas são maiores e vão evaporando à medida que caem no solo. No fog, as gotas ficam suspensas no ar e evaporam antes de tocar o solo. BUCKLIN \& BRAY et al. (1998) relataram que o sistema fog é operado com pressurização acima de $1 \mathrm{MPa}$.

Embora a utilização de água para resfriar o ambiente de uma instalação proporcione efeitos benéficos, no que se refere principalmente à redução da temperatura do ar, alguns pesquisadores alertaram para problemas associados ao uso de água em regiões úmidas, ou melhor, em períodos chuvosos. SINGLETARY et al. (1996) observaram que, em períodos chuvosos, os sistemas de nebulização poderiam aumentar excessivamente a umidade relativa dentro da instalação, o que seria 
prejudicial para o animal em termos de conforto térmico. Da mesma forma, BUCKLIN \& BRAY (1998) relataram que os sistemas de resfriamento evaporativo são mais eficientes em épocas ou em regiões que apresentam baixa umidade relativa. JOHNSON \& VANJONACK (1976) consideraram 76\% uma umidade relativa alta e relataram que, à mesma temperatura, a variação de umidade de 38 para $76 \%$ reduziu a produção de leite de vacas holandesas e Jersey.

O objetivo deste trabalho foi avaliar o ambiente térmico, com base em índices de conforto térmico medidos em instalações para gado de leite, dotadas de diferentes recursos de acondicionamento.

\section{MATERIAL E MÉTODOS}

O trabalho foi realizado na Faculdade de Zootecnia e Engenharia de Alimentos (FZEA/USP), em Pirassununga - SP, durante o verão de 2002.

Na Figura 1, são apresentados os três tratamentos (instalações) de forma esquemática, com o posicionamento e as dimensões das instalações do experimento. Foram utilizados animais da raça Holandesa preta e branca: 17 multíparas com média de produção de $5.500 \mathrm{~kg}$ de leite por lactação e 10 primíparas entre o segundo e o sétimo mês do estágio de lactação. Para cada tratamento (instalação), foram distribuídos, por sorteio, animais das duas categorias. A discussão dos resultados referentes aos animais foi apresentada por MARTELLO et al. (2002).

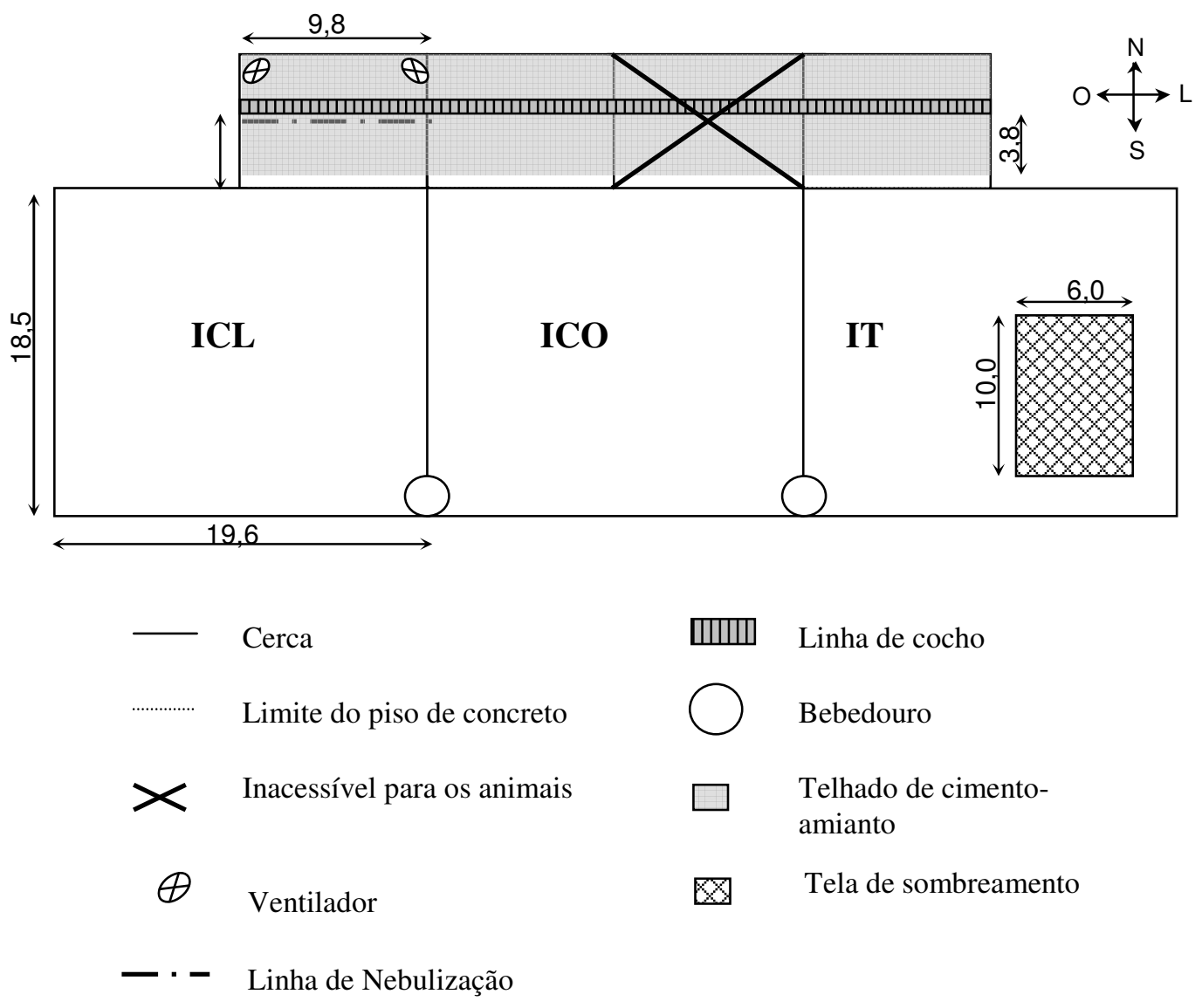

FIGURA 1. Esquema e dimensões das instalações-controle (ICO), climatizada (ICL) e tela (IT). Medidas em metros. Sem escala. 
As três instalações apresentavam área com piquete adjacente descoberto, de $362 \mathrm{~m}^{2}$, e com características iguais no que se refere à estrutura construtiva da área de comedouro, a saber: pé-direito igual a 3,5 m, área de comedouro coberta acessível aos animais, de 3,8 x 9,8 m, telhado tipo duas águas, com estrutura metálica e telha de cimento-amianto de $5 \mathrm{~mm}$ de espessura e inclinação de $17 \%$, sem pintura externa. A instalação-controle (ICO) contou com o sombreamento de $37,2 \mathrm{~m}^{2}$ oferecido pela cobertura do comedouro com telha de cimento-amianto. $\mathrm{Na}$ instalação climatizada (ICL), foram instalados dois ventiladores e uma linha de aspersão (mist) a 3,0 m do solo, sobre os comedouros na área coberta, com oito bicos, eqüidistantes de $1 \mathrm{~m}$, com vazão de 7,8 $\mathrm{L} \mathrm{h}^{-1}$ por bico. Os ventiladores foram programados para ligar a partir da temperatura do ar de $24{ }^{\circ} \mathrm{C}$, e os aspersores eram acionados a partir da temperatura de $26^{\circ} \mathrm{C}$. No piquete da instalação com tela (IT), foi instalada uma cobertura de $60 \mathrm{~m}^{2}$ de tela preta de polietileno com malha para $80 \%$ de sombra, colocada em camada única sobre estrutura de madeira, sem fechamento lateral e com pé-direito de 3,5 m.

Para cada tratamento, foram calculados os índices ITU e ITGU, descritos nas eqs.(1) e (2).

$$
\begin{aligned}
& \text { ITU }=\text { TBS }+0,36 \text { To }+41,5 \\
& \text { ITGU }=\text { TG + 0,36 To }+41,5
\end{aligned}
$$

em que,

TBS - temperatura do bulbo seco, ${ }^{\circ} \mathrm{C}$;

To - temperatura do ponto de orvalho, ${ }^{\circ} \mathrm{C}$, e

TG - temperatura do globo negro, ${ }^{\circ} \mathrm{C}$.

Para a análise dos dados, selecionaram-se os dias em que a entalpia das 13 h, horário mais quente do dia, do tratamento-controle, esteve acima da considerada crítica. Entalpia é a variável física que indica a quantidade de calor contida em uma mistura de ar seco (NÄÄS et al., 1995).

Considerou-se crítica a entalpia a partir de $63,5 \mathrm{~kJ} \mathrm{~kg}^{-1}$ de ar seco, obtida a partir da temperatura de $24{ }^{\circ} \mathrm{C}$ e da umidade relativa do ar de 76\% (JOHNSON \& VANJONACK, 1976). Foram observados 26 dias nessa condição e toda análise refere-se a esses dias. Para o cálculo da entalpia, utilizou-se o programa computacional PsyCalc $98^{\circledR}$ (Monterrey Institute of Technology), que considera a temperatura do bulbo seco $\left({ }^{\circ} \mathrm{C}\right)$, a umidade relativa do ar $(\%)$ e a pressão barométrica local, cuja média adotada foi de $603,14 \mathrm{~mm} \mathrm{Hg}$.

Para a obtenção das temperaturas do bulbo seco (TBS), foram utilizados termômetros de coluna de mercúrio, com escala de $-30 \mathrm{a}+50{ }^{\circ} \mathrm{C}$ e sensibilidade de $1{ }^{\circ} \mathrm{C}$. Para a coleta de temperatura do globo (TG), foram utilizados termômetros de globo, confeccionados com bóias plásticas (NÄ̈̈S \& ARCARO JÚNIOR, 2001) esféricas de 22,3 cm de diâmetro externo, pintadas com tinta preta fosca, sendo inseridos em seu interior termômetros de mercúrio, com escala variando de -10 a $+60{ }^{\circ} \mathrm{C}$ e sensibilidade de $1{ }^{\circ} \mathrm{C}$. A inserção foi feita de tal modo que o reservatório de mercúrio do termômetro ficasse no centro geométrico da esfera. Para a medida da umidade relativa (UR), utilizou-se um termoigrômetro com escala de 0 a $100 \%$ e precisão de $5 \%$. Os equipamentos foram instalados a $1,80 \mathrm{~m}$ do solo, em todos os tratamentos.

As análises dos efeitos dos tratamentos foram realizadas por meio do procedimento Mixed do programa SAS (1998), e as médias dos tratamentos foram comparadas por quadrados mínimos, ajustados pelo teste de Bonferroni.

\section{RESULTADOS E DISCUSSÃO}

Na Tabela 1, encontram-se os valores médios dos parâmetros climáticos para cada tratamento (instalação), nos diferentes horários. Houve interação entre instalação e hora $(\mathrm{p}<0,01)$. 
Com relação à TBS, nas três instalações, no horário das $8 \mathrm{~h}$, os valores estiveram dentro da faixa de conforto para vacas em lactação, considerada entre $4^{\circ}$ e $24{ }^{\circ} \mathrm{C}$ por NÄ̈̈S (1989). ARCARO JÚNIOR et al. (2001) também compararam três sistemas de instalação, no período de maio a outubro, e não observaram diferenças nas TBSs entre os tratamentos nesse mesmo horário. Os valores relatados pelos autores foram 19,3; 19,0 e 18,4 ${ }^{\circ} \mathrm{C}$ para instalações com sombra desprovida de equipamentos de climatização, sombra mais ventilação e sombra com ventilação e aspersão, respectivamente.

TABELA 1. Médias das temperaturas do ar (TBS) e temperatura do globo negro (TG), em ${ }^{\circ} \mathrm{C}$, e umidade relativa (UR), em \%, nos tratamentos-controle (ICO), climatizado (ICL) e tela (IT), nos diferentes horários

\begin{tabular}{ccccc}
\hline \multirow{2}{*}{ Variáveis } & \multirow{2}{*}{ Horários } & \multicolumn{3}{c}{ Tratamentos } \\
\cline { 2 - 5 } & $8 \mathrm{~h}$ & $23,7^{\mathrm{a}}$ & ICL & IT \\
\hline \multirow{3}{*}{ TBS } & $11 \mathrm{~h}$ & $29,3^{\mathrm{a}}$ & $23,0^{\mathrm{a}}$ & $23,8^{\mathrm{a}}$ \\
& $13 \mathrm{~h}$ & $30,8^{\mathrm{a}}$ & $26,9^{\mathrm{b}}$ & $30,8^{\mathrm{a}}$ \\
& $17 \mathrm{~h}$ & $27,0^{\mathrm{a}}$ & $25,5^{\mathrm{a}}$ & $31,4^{\mathrm{a}}$ \\
& $8 \mathrm{~h}$ & $24,1^{\mathrm{AB}}$ & $23,2^{\mathrm{B}}$ & $25,0^{\mathrm{a}}$ \\
\hline \multirow{2}{*}{ TG } & $11 \mathrm{~h}$ & $30,0^{\mathrm{A}}$ & $26,7^{\mathrm{B}}$ & $30,6^{\mathrm{A}}$ \\
& $13 \mathrm{~h}$ & $31,8^{\mathrm{A}}$ & $27,4^{\mathrm{B}}$ & $32,4^{\mathrm{A}}$ \\
& $17 \mathrm{~h}$ & $27,3^{\mathrm{A}}$ & $25,7^{\mathrm{A}}$ & $28,3^{\mathrm{A}}$ \\
\hline \multirow{2}{*}{ UR } & $8 \mathrm{~h}$ & $83,1^{\mathrm{a}}$ & $87,0^{\mathrm{a}}$ & $77,1^{\mathrm{b}}$ \\
& $11 \mathrm{~h}$ & $62,7^{\mathrm{b}}$ & $73,7^{\mathrm{a}}$ & $56,8^{\mathrm{b}}$ \\
& $13 \mathrm{~h}$ & $56,5^{\mathrm{b}}$ & $71,2^{\mathrm{a}}$ & $49,8^{\mathrm{b}}$ \\
& $17 \mathrm{~h}$ & $69,4^{\mathrm{ab}}$ & $77,1^{\mathrm{a}}$ & $62,8^{\mathrm{b}}$ \\
\hline
\end{tabular}

Médias seguidas de letras minúsculas distintas na mesma linha e maiúsculas na mesma coluna diferem $(\mathrm{p}<0,01)$ pelo teste de Bonferroni.

As temperaturas mais elevadas foram observadas às 11 e às $13 \mathrm{~h}$ nas três instalações. Os equipamentos de climatização propiciaram, nesses horários, reduções na TBS de 2,9 e $3,9{ }^{\circ} \mathrm{C}(10$ e $13 \%$ ), respectivamente, em relação ao tratamento ICO. FRAZZI et al. (1997) compararam instalações equipadas com ventiladores associados a aspersores e instalações somente com ventiladores e observaram reduções de até $3{ }^{\circ} \mathrm{C}$ na TBS do tratamento com ventiladores e aspersores em relação ao outro tratamento.

Ressalta-se, entretanto, que às 11 e às 13 h, mesmo sob influência dos equipamentos, as temperaturas no tratamento ICL mantiveram-se 0,4 e $0,9{ }^{\circ} \mathrm{C}$, respectivamente, acima da considerada por HUBER (1990) como estressante para vacas em lactação $\left(26{ }^{\circ} \mathrm{C}\right)$. Isso pode indicar que os equipamentos (ventiladores e aspersores) devam ser acionados antes de a temperatura do ar atingir o limite crítico para as vacas.

Para a temperatura do globo negro, às $8 \mathrm{~h}$, o microclima do tratamento ICL não estava sob a influência dos equipamentos de climatização, o que justifica o fato de as médias de ICL e ICO não terem diferido estatisticamente entre si (Tabela 1). Já, entre os tratamentos ICL e IT, ocorreu diferença $(\mathrm{p}<0,01)$ de $2,6^{\circ} \mathrm{C}$. Às $11 \mathrm{~h}$, observou-se diferença significativa $(\mathrm{p}<0,05)$ entre o tratamento ICL e os tratamentos ICO e IT, sendo que ICO e IT não apresentaram diferença entre si. A redução de 3,3 e $3,9^{\circ} \mathrm{C}$, na TG do tratamento ICL, em relação ao ICO e IT, nessa ordem, deveu-se, provavelmente, à eficiência dos equipamentos de climatização. De acordo com GUISELINI et al. (1999), a redução de $0,5^{\circ} \mathrm{C}$ em ambientes abertos, similares às instalações do presente trabalho, tem influência considerável no conforto térmico do ambiente. 
Os resultados indicaram contribuição positiva dos equipamentos de climatização, no que se refere à temperatura do globo negro, no ICL, sobretudo no período mais quente do dia. Às $13 \mathrm{~h}$, observaram-se reduções significativas $(\mathrm{p}<0,05)$ de 4,4 e $5,0{ }^{\circ} \mathrm{C}$, em relação aos tratamentos ICO e IT, respectivamente.

Às $17 \mathrm{~h}$, as temperaturas do globo negro, nas três instalações, não foram diferentes entre si. Entretanto, o tratamento ICL apresentou valor absoluto menor do que os dos tratamentos ICO e IT, o que provavelmente esteve associado ao efeito dos ventiladores que, nesse horário, ainda estavam ligados.

Às 11 e às $13 \mathrm{~h}$, observou-se que a UR do tratamento ICL foi significativamente maior $(\mathrm{p}<0,01)$ se comparada aos outros dois tratamentos, e esses não apresentaram diferença significativa entre si. As médias mais altas de UR observadas no tratamento ICL, nestes horários, foram mantidas pelo funcionamento do equipamento de aspersão, que permanecia ligado nesse período, em razão das altas temperaturas.

Registraram-se, às 13 h, os menores valores absolutos de UR para as três instalações. Isso está de acordo com BUCKLIN \& BRAY (1998), que relataram URs mais baixas associadas às temperaturas do bulbo seco mais elevadas. Também nesse horário, registrou-se a maior diferença de UR entre ICL e ICO, sendo que a UR de ICL foi $26 \%$ acima da UR do ICO. Esses valores estão acima dos observados por FRAZZI et al. (1997), em instalações parcialmente fechadas, que registraram aumento de até $15 \%$ na UR em instalação equipada com aspersores e ventiladores em relação à instalação equipada somente com ventiladores.

Esses resultados indicaram que a utilização de sistema de aspersão (mist), em época de altas umidades relativas (verão chuvoso), pode causar aumento excessivo da UR dentro da instalação, o que está de acordo com o relatado por SINGLETARY et al. (1996). Esses pesquisadores alertaram que, em dias úmidos, os sistemas de aspersão podem inserir mais água do que possa ser evaporada nas instalações, e assim deixar o ambiente excessivamente úmido. Sugere-se, portanto, a realização de novas pesquisas com o objetivo de estabelecer o manejo adequado de sistemas de resfriamento evaporativo, por meio de aspersão associada à ventilação, principalmente para regiões com alta umidade.

Em relação à entalpia, foi observada iteração significativa $(\mathrm{p}<0,01)$ entre instalação e hora (Figura 2).

Às $8 \mathrm{~h}$, foram observados valores médios de 66,$3 ; 66,4$ e $62,7 \mathrm{~kJ} \mathrm{~kg}^{-1}$ de ar seco nos tratamentos ICO, ICL e IT, respectivamente. Destaca-se que a entalpia média do IT foi menor $(\mathrm{p}<0,01)$, se comparada ao ICO e ICL, e esteve abaixo do valor considerado crítico neste trabalho $\left(63,5 \mathrm{~kJ} \mathrm{~kg}^{-1} \mathrm{de}\right.$ ar seco). Essa entalpia crítica baseou-se na temperatura e na umidade relativa limites para vacas de leite, cujos valores adotados foram $24{ }^{\circ} \mathrm{C}$ e $76 \%$, respectivamente (JOHNSON \& VANJONACK, 1976). Os demais tratamentos apresentaram entalpias superiores a esse valor.

Às $11 \mathrm{~h}$, não foram observadas diferenças significativas entre as médias do ICO, do ICL e do IT (73,2; 70,3 e 68,1 $\mathrm{kJ} \mathrm{kg}^{-1}$ de ar seco, respectivamente).

As médias das entalpias, às $13 \mathrm{~h}$, apresentaram valores de 74,1;71,2 e 70,8 kJ kg-1 de ar seco para ICO, ICL e IT, respectivamente, sem diferença significativa entre elas. Às $17 \mathrm{~h}$, não foram observadas diferenças significativas entre ICO e ICL, com valores de 69,3 e $69,1 \mathrm{~kJ} \mathrm{~kg}^{-1} \mathrm{de}$ ar seco, respectivamente. Já a entalpia de $63,7 \mathrm{~kJ} \mathrm{~kg}^{-1}$ de ar seco do tratamento IT foi menor $(\mathrm{p}<0,01)$ comparada aos outros dois tratamentos, o que demonstra que o sombreamento (com tela) foi mais efetivo nas horas mais frescas. 


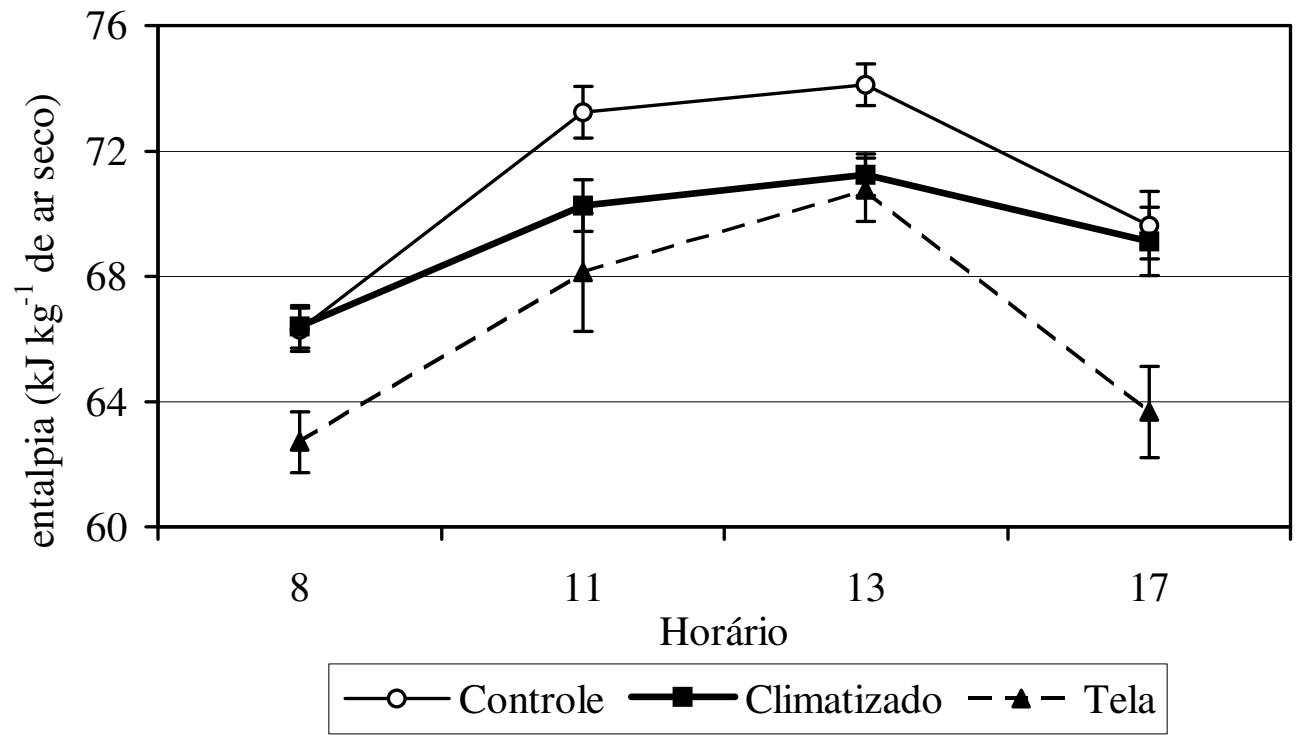

FIGURA 2. Médias e erro-padrão das médias de entalpia das diferentes instalações nos horários analisados.

Em casos de mudança de umidade relativa, para uma mesma temperatura, a energia envolvida nesse processo se altera e, conseqüentemente, a troca térmica que ocorre no ambiente também sofre alteração. Isso foi bastante evidente no tratamento IT, sobretudo às 8 e às $17 \mathrm{~h}$, em que a entalpia foi menor, embora as TBSs dos três tratamentos fossem semelhantes. Essa menor entalpia no tratamento IT, provavelmente, deveu-se às menores umidades relativas registradas nesses horários, em comparação com os outros dois tratamentos.

Ressalta-se, também, que as menores $(\mathrm{p}<0,01)$ temperaturas do ar do ICL, nos horários mais quentes (11 e $13 \mathrm{~h}$ ) do dia (Tabela 1), não permitiram manter um valor de entalpia também menor, comparado às outras duas instalações. Tal fato deve ter ocorrido em razão das altas umidades relativas registradas no ICL nesses horários.

O uso da intermitência nos equipamentos de aspersão parece favorecer o equilíbrio da umidade relativa dentro das instalações climatizadas (ROMA JÚNIOR et al., 2001), sobretudo ao se considerar a inércia da entalpia em uma instalação semi-aberta. No entanto, no presente trabalho, o equipamento utilizado não permitia intermitência, o que, provavelmente, contribuiu para a alta umidade dentro da instalação ICL. Estudos adicionais seriam de interesse, a fim de determinarem períodos adequados de intermitência, considerando-se a espécie animal, a localização (região), a época do ano, a operacionalidade e os custos do sistema de resfriamento.

A análise desses dados indicou que a utilização de coberturas com tela de $80 \%$ de sombreamento foi uma boa opção para a redução da entalpia em períodos críticos, uma vez que, dentre as instalações estudadas, a IT foi a que apresentou entalpia média menor, em valores absolutos.

Foi observada uma iteração significativa entre instalação e hora $(\mathrm{p}<0,01)$ em relação ao ITU (Figura 3). Às 8 h, as médias de ITU foram 72,2; 71,8 e 71,8 para ICO, ICL e IT, respectivamente, sem diferença entre os tratamentos.

Às 11 h, observou-se ITU de 78,2; 75,3 e 77,9, nos tratamentos ICO, ICL e IT, respectivamente. O ITU do tratamento ICL foi menor $(\mathrm{p}<0,01)$ do que o dos tratamentos ICO e IT, sendo que estes últimos não apresentaram diferença significativa entre si. Às $13 \mathrm{~h}$, a média do tratamento ICL foi menor $(\mathrm{p}<0,01)$ que a dos tratamentos $\operatorname{ICO}$ e IT $(75,7 ; 79,4$ e 79,5, respectivamente). As médias de ICO e IT não diferiram entre si. 


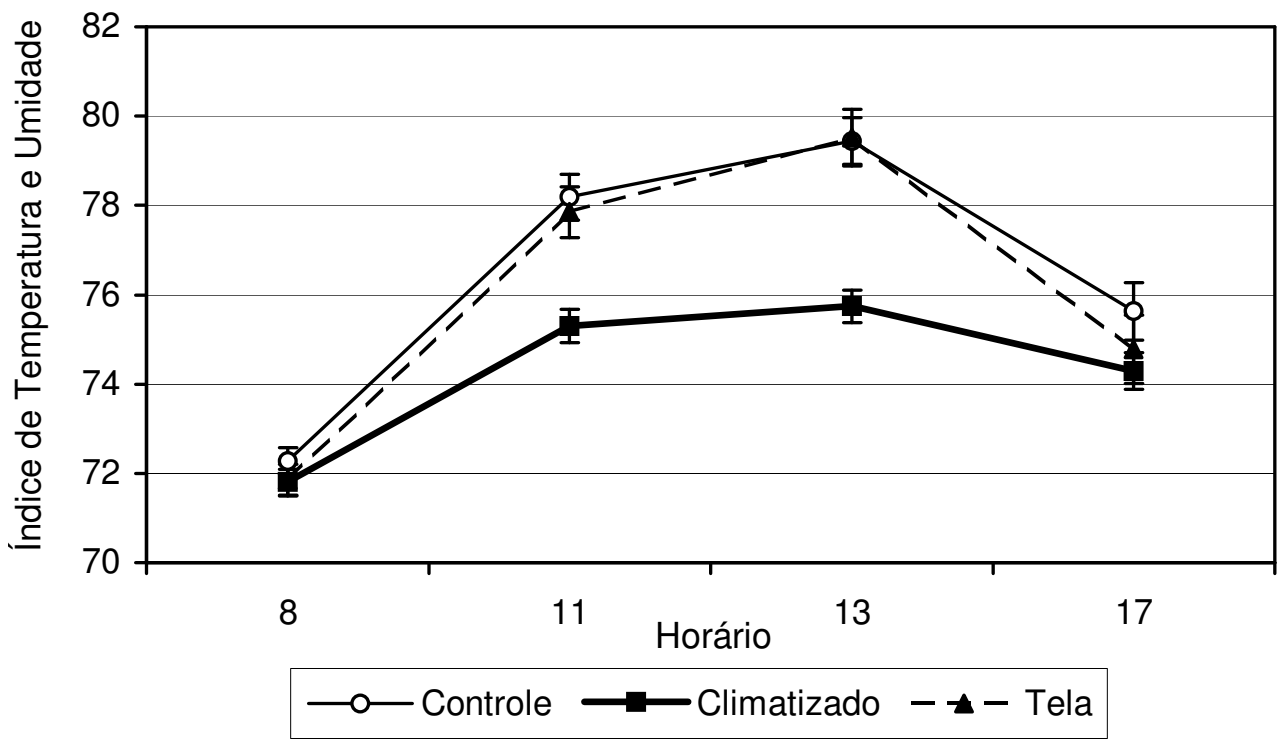

FIGURA 3. Médias e erro-padrão das médias do índice de temperatura e umidade das diferentes instalações nos horários analisados.

Provavelmente, os maiores valores de ITU no ICO e no IT, às $11 \mathrm{~h}$ e às $13 \mathrm{~h}$, ocorreram em razão das altas TBSs registradas nesses horários, uma vez que as URs estiveram abaixo de $70 \%$. NÄÄS \& ARCARO JÚNIOR (2001) relataram que a melhor maneira de resfriar o ambiente destinado a animais em lactação seria pelo uso da água, desde que a UR estivesse até o limite aproximado de $70 \%$.

Embora o tratamento ICL tenha apresentado valores de ITU menores que os dos demais tratamentos, esses valores encontraram-se acima do limite crítico (72) para vacas em lactação (HAHN, 1985 e JOHNSON, 1980), possivelmente em razão das altas URs registradas nessa instalação. Nesse ponto, ressalta-se o desafio de climatizar o ambiente por meio da aspersão (mist), sobretudo nos períodos de ocorrência de altas URs no ambiente externo. Às 17 h, as médias foram 75,6; 74,3 e 74,8, para ICO, ICL e IT, respectivamente, e não apresentaram diferença significativa entre si.

Para o ITGU, foi observada uma interação significativa $(\mathrm{p}<0,01)$ entre instalação e horário (Figura 4). Às 8 h, as médias de ITGU foram 73,2; 72,2 e 74,2, para ICO, ICL e IT, respectivamente, sem diferença significativa entre eles. Às $11 \mathrm{~h}$, observou-se que o ITGU do tratamento ICL foi menor $(\mathrm{p}<0,01)$ do que os dos tratamentos ICO e IT $(75,9 ; 79,2$ e 79,2, respectivamente).

Às $13 \mathrm{~h}$, os tratamentos ICO, ICL e IT apresentaram médias de ITGU de 80,9; 76,7 e 80,7, respectivamente. Observou-se que o valor para o tratamento ICL foi menor $(\mathrm{p}<0,01)$ do que os dos tratamentos ICO e IT, e que os dois últimos não apresentaram diferença significativa entre si. Os valores do tratamento ICO foram próximos dos relatados por SLEUTJES \& LIZIERIE (1991), que encontraram, em tardes quentes de verão (TBS de 30 a $38{ }^{\circ} \mathrm{C}$ ), ITGU de 82,2 para instalação aberta e bem ventilada, com pé-direito alto e comedouro coberto com telhas de cimento-amianto.

Às 17 h, não foi observada diferença entre os três tratamentos, que apresentaram médias de 76,3; 74,8 e 76,4 para os tratamentos ICO, ICL e IT, respectivamente.

Destaca-se que, nos horários mais quentes, o ICL apresentou valores de ITGU menores ( $\mathrm{p}<0,01)$ em comparação aos outros dois tratamentos, em razão dos efeitos provocados pelo funcionamento dos ventiladores e dos aspersores. 


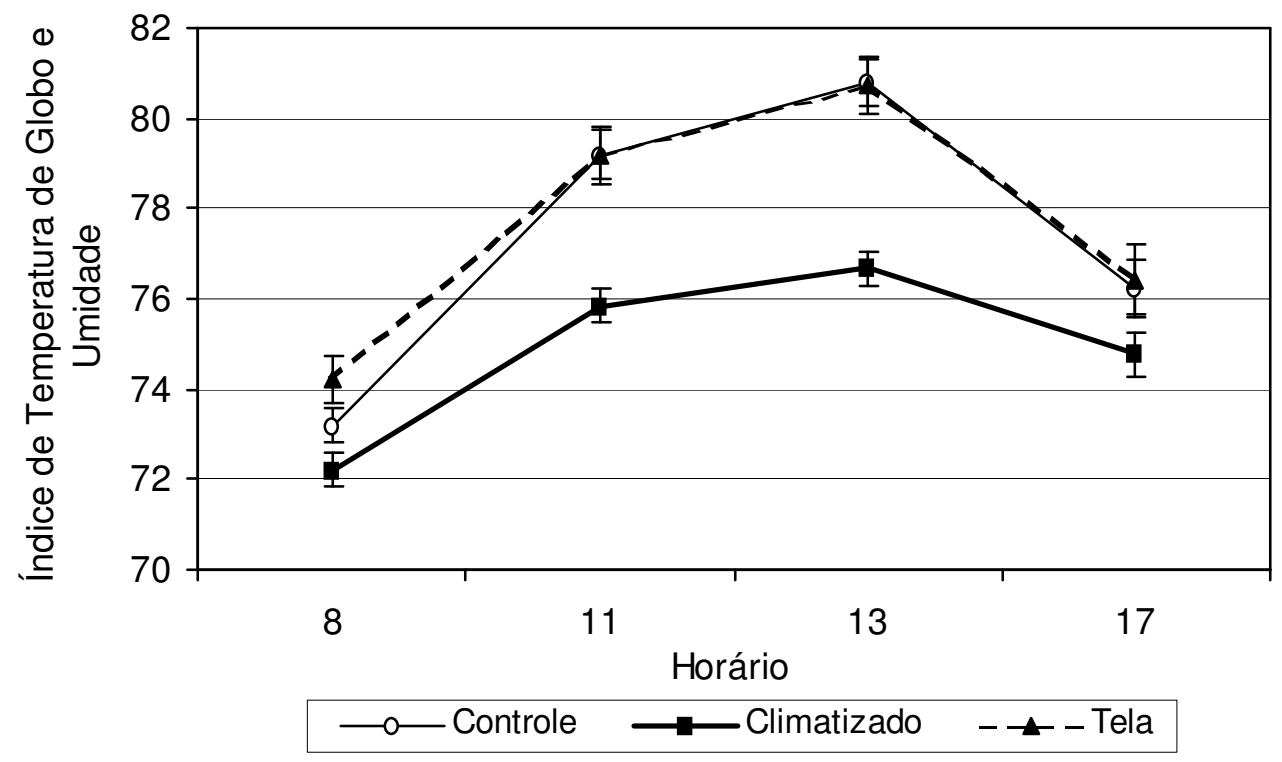

FIGURA 4. Médias e erro-padrão das médias do índice de temperatura de globo negro e umidade das diferentes instalações nos horários analisados.

\section{CONCLUSÕES}

Os índices de temperatura e umidade (ITU) e de temperatura do globo e umidade (ITGU), nos horários mais quentes do dia, diferenciaram-se para a instalação climatizada, que apresentou melhor desempenho em relação às demais.

O sistema de aspersão (mist), utilizado na instalação climatizada, manteve, nos horários mais quentes do dia, ITU menor do que as demais instalações, embora tenha apresentado valores acima do limite crítico (ITU $=72)$ para vacas em lactação.

A utilização da tela de sombreamento apresentou valores de entalpia abaixo ou semelhantes à cobertura de cimento-amianto e à cobertura climatizada, valores esses associados à menor umidade relativa do ar na instalação com tela.

Dentre as instalações avaliadas, tanto a instalação climatizada (ICL) como a instalação com tela (IT) apresentaram resultados satisfatórios para proporcionar conforto aos animais.

\section{REFERÊNCIAS BIBLIOGRÁFICAS}

ALBRIGHT, J.L. Feeding behaviour of dairy cattle. Journal of Dairy Science, Champaign, v.76, n.2, p.485-91, 1993.

ARCARO JÚNIOR, I.; ARCARO, J.R.P.; POZZI, C.R.; MATARAZZO, S.V.; FAGUNDES, H. Produção e composição do leite de vacas holandesas em sala de espera climatizada. In: CONGRESSO BRASILEIRO DE BIOMETEOROLOGIA, 3., 2001, Maringá. Anais...2001. 6 p.

BACCARI JÚNIOR, F. Manejo ambiental para produção de leite em climas quentes. In: CONGRESSO BRASILEIRO DE BIOMETEOROLOGIA, 3., 1998, Goiânia. Anais... Goiânia: Sociedade Brasileira de Biometeorologia, 1998. p.136-61.

BACCARI JÚNIOR, F. Manejo ambiental da vaca leiteira em climas quentes. Londrina: Ed.UEL, 2001. 142 p. 
BRAY D.R.; BUCKLIN, R.A.; MONTOYA, R.; GIESY, R. Cooling methods for dairy housing in the southeastern United States. Transactions of ASAE, St. Joseph, 1994. p.1-15 (Paper. n 94-4501)

BUCKLIN, R.A.; BRAY, E.R. The american experience in dairy management in warm and hot climates. In: SIMPÓSIO BRASILEIRO DE AMBIÊNCIA NA PRODUÇÃO DE LEITE, 1., 1998, Piracicaba. Anais... Piracicaba: FEALQ, 1998. p.156-74.

BUFFINGTON, D.E.; COLLAZO-AROCHO, A.; CANTON, G.H.; PITT, D.; TAHTCHER, W.W.; COLLIER, R.J. Black globe-humidity index (ITGU) as confort equation for dairy cows. Transactions of ASAE, St. Joseph, v.24, n.3, p.711-14, 1981.

CARGILL, B.F.; STEWART, R.E. Effect of humidity on total heat and total vapor dissipation of Holstein cows. Transactions of ASAE, St. Joseph, v.9. p.701-6, 1966.

FRAZZI, E.; CALAMARI, L.; CALEGARI, F.; MAIANTI, M.G.; CAPPA, V. The aeration with and without misting: Effects on heat stress in dairy cows. In: SIMPOSIUM AGRICULTURAL

ENGINEERING, 5., 1997, Minnesota. Proceedings...1997. p.907-14.

GUISELINI, C.; SILVA, I.J.O., PIEDADE, S.M. Avaliação da qualidade do sombreamento arbóreo no meio rural. Revista Brasileira de Engenharia Agrícola e Ambiental, Campina Grande, v.3, n.3, p.380-4, 1999.

HAHN, G.L. Management and housing of farm animals in hot environments. In: YOSEF, M.K. (Ed). Stress physiology in livestock. Boca Raton: CRC Press, 1985. p.151-74.

HUBER, J.T. Alimentação de vacas de alta produção sob condições de stress térmico. In: HUBER, J.Y. Bovinocultura leiteira. Piracicaba: FEALQ, 1990. p.33-48.

JOHNSON, H.D.; RAGSDALE, A.C.; BERRY, I.L.; SHANKLIN, M.D. Effect of various temperature-humidity combinations on milk production of Holstein cattle. Missouri: Agricultural Experimental Station Research Bulletin, 1962. p.791.

JOHNSON, H.D.; VANJONACK, W.J. Effects of environmental and other stressors on blood hormone patterns in lactating animals. Journal of Dairy Science, Champaign, v.59, n.9, p.1603-17, 1976.

JOHNSON, H.D. Environmental management of cattle to minimize the stress of climatic change. International Journal of Biometeoroly, Lisse, v.24, p.65-78, 1980.

KELLY, C.F.; BOND, T.E. Bioclimatic factors and their measurement.Washington: National Academy of Sciences: a guide to environmental research on animals, 1971. 7 p.

MARTELLO, L.S.; SAVASTANO JÚNIOR, H.; SILVA, S.L.; TITTO, E.A.L.; PEREIRA, A.M.F. Avaliação do consumo e produção de leite de multíparas e primíparas submetidas a diferentes ambientes. In: CONGRESSO DE ZOOTECNIA, 12., 2002, Villa Real. Anais... Villa Real: Associação Portuguesa dos Engenheiros Zootécnicos, 2002. p.470-3.

NÄÄS, I.A. Princípios de conforto térmico na produção animal. São Paulo: Ícone Ed., 1989. 183 p. NÄÄS, I.A.; MOURA, D.J.; LAGANÁ, C.A. Utilização da entalpia como variável física de avaliação do conforto térmico na avicultura de corte. In: CONFERÊNCIA APINCO DE CIÊNCIA E TECNOLOGIA E AVÍCOLAS, 1., 1995, Curitiba. Anais... Campinas: Facta, 1995. p.201-2.

NÄÄS, I.A.; SILVA, I.J.O. Técnicas modernas para melhorar a produtividade dos suínos através do controle ambiental. In: BALBUENA et al. (Eds.) Ingenieria Rural y Mecanización en el Ambito Latinoamericano. La Plata: Editorial de la UNLP, 1998. p.464-72. 
NÄAS, I.A.; ARCARO JÚNIOR, I. Influência de ventilação e aspersão em sistemas de sombreamento artificial para vacas em lactação em condições de calor. Revista Brasileira de Engenharia Agrícola e Ambiental, Campina Grande, v.5, n.1, p.139-42, 2001.

ROMA JÚNIOR., L.C.; SILVA, I.J.O.; PINHEIRO, M.G.; PIEDADE, S.M.S. Avaliação física do sistema de resfriamento adiabático evaporativo (SRAE) em instalações do tipo freestall para bovinos de leite. In: CONGRESSO BRASILEIRO DE ENGENHARIA AGRÍCOLA, 30., 2001, Foz do Iguaçu. Anais... Cascavel: Sociedade Brasileira de Engenharia Agrícola, 2001. 1 CD ROM.

SAS/STAT. User's Guide. Version 6. 4. ed.. Cary: SAS Institute, 1998. v.2. 943 p.

SINGLETARY, I.B; BOTTCHER, R.W.; BAUGHMAN, G.R. Characterizing effects of temperature and humidity on misting evaporative efficiency. Transactions of ASAE, St. Joseph, v.39, n.5, p.1801-9, 1996.

SLEUTJES, M.A.; LIZIERIE, R.S. Conforto térmico do gado leiteiro. In: SEMINÁRIO INTERNACIONAL DE CONSTRUÇÕES RURAIS - AGRIBUILDING, 1., 1991, Campinas. Anais... Campinas: UNICAMP, 1991. p.25.

THOM, E.C. The discomfort index. Weatherwise, Washington, v.12, n.7, p.57-9, 1959. 